\title{
Common pulmonary veins anatomic variants assesed by routine preprocedural multislice computed tomography angiography and its impact on success of atrial fibrillation ablation - single center experience in 75 cases
}

Ante Anić*, Zoran Bakotić, Marin Bištirlić, Krešimir Librenjak, Iva Pavić, Mladen Harapin, Damir Kasap, Albino Jović

Background: Electrical pulmonary vein isolation (PVI) has become an effective tool to control atrial fibrillation (AF). Point by point ablation guided by electroanatomical mapping system is a preferable method of achieving it. Most electrophysiology (EP) labs routinely employ some kind of preprocedural imaging to gain insight into PV anatomical variants that could alter the strategy of ablation procedure. On the other hand there is scarce data on correlation of knowledge of pulmonary vein (PV) anatomy on success, duration and safety of the procedure.

Methods: From November 2009 till March 2013 we performed 75 AF ablations in General Hospital Zadar, EP lab. All patients underwent preprocedural left atrial and pulmonary veins MSCT angiography using Siemens Somatom 16. 3D reconstructions were made with standard software and operators were aware of the anatomy. Patients were divided into 2 groups depending on anatomical variants of PVs: Group A - standard anatomy in whom all 4 PVs connect to LA with separated ostia and Group B - any other anatomical variant. We then correlated the anatomy with outcomes in terms of success, duration and safety of the ablation procedure.

Results: The most common anatomical variant we met in our cohort was a common left trunk in $17 \%$ of patients (13/75). Accessory PVs were registered in 14\% (11/75). We had a rare case of accessory right PV connecting to LA roof in one patient. The mean procedure duration was $214 \pm 49$ minutes in Group A vs $208 \pm 44$ in Group B $(P=0.71)$. There was no difference in success defined as clinical improvement in AF burden. No patient reported symptoms suggestive of PV stenosis.

Conclusions: Variants in PV anatomy in our cohort, as assessed by MCST angiography were as common as described in previously published studies. The presence of common left PV trunk shows a trend toward shortening the overall procedure time but has a same success rate in short term follow up. None of the anatomical variants influenced the safety outcomes.

KEYWORDS: pulmonary vein anatomy, atrial fibrillation ablation, MSCT angiography, left pulmonary vein common trunk, accessory pulmonary veins.

\section{Received: $20^{\text {th }}$ Mar 2013}

*Address for correspondence: Opća bolnica Zadar, B. Peričića 5, HR-23000 Zadar, Croatia.

Phone: +385-23-505-505

E-mail: anteanic@gmail.com

\section{Literature}

1. den Uijl DW, Tops LF, Delgado V, et al. Effect of pulmonary vein anatomy and left atrial dimensions on outcome of circumferential radiofrequency catheter ablation for atrial fibrillation. Am J Cardiol. 2011;107(2):243-9.

2. Cappato R, Calkins H, Chen SA, et al. Updated worldwide survey on the methods, efficacy, and safety of catheter ablation for human atrial fibrillation Circ Arrhythm Electrophysiol 2010;3:32-8.

3. Anić A. Catheter ablation for atrial fibrillation. Cardiol Croat. 2010;5(3-4):33-6. 